\title{
The I105V polymorphism in glutathione S-transferase P1, parental smoking and the risk for nonsyndromic cleft lip with or without cleft palate
}

Ingrid PC Krapels ${ }^{1,2,9}$, Judith Raijmakers-Eichhorn ${ }^{3}$, Wilbert HM Peters ${ }^{3}$, Hennie MJ Roelofs ${ }^{3}$, Frank Ras ${ }^{4}$, Régine PM Steegers-Theunissen ${ }^{\star 1,5,6,7,8}$ and the Eurocran Gene-Environment Interaction Group

\footnotetext{
${ }^{1}$ Department of Epidemiology and Biostatistics, Radboud University Nijmegen Medical Center, Nijmegen, The Netherlands; ${ }^{2}$ Department of Orthodontics and Oral Biology, Radboud University Nijmegen Medical Center, Nijmegen, The Netherlands; ${ }^{3}$ Department of Gastroenterology, Radboud University Nijmegen Medical Center, Nijmegen, The Netherlands; ${ }^{4}$ Department of Oral and Maxillofacial Surgery, University Medical Center Leiden, Leiden, The Netherlands; ${ }^{5}$ Division of Obstetrics and Prenatal Medicine, Department of Obstetrics and Gynecology, Erasmus MC, University Medical Center, Rotterdam, The Netherlands; ${ }^{6}$ Department of Clinical Genetics, Erasmus MC, University Medical Center, Rotterdam, The Netherlands; ${ }^{7}$ Department of Epidemiology and Biostatistics, Erasmus MC, University Medical Center, Rotterdam, The Netherlands; ${ }^{8}$ Division of Pediatric Cardiology, Department of Pediatrics, Erasmus MC, University Medical Center, Rotterdam, The Netherlands
}

Genetic variations in the detoxification enzyme glutathione S-transferase P1 (GSTP1) may modify the teratogenicity of lifestyles, such as smoking. We investigated the role of the 1105V polymorphism in GSTP1, parental periconception smoking, and their interaction with nonsyndromic cleft lip with or without cleft palate (CL/P) risk in the offspring. The GSTP1 I105V polymorphisms were determined in Dutch nonconsanguineous Caucasians comprising of $155 \mathrm{CL} / \mathrm{P}$ triads (mother, father, child) and 195 control triads. The analyses were also carried out on complete triads only ( $n=69 \mathrm{CL} / \mathrm{P}$ and $n=95$ controls). Transmission disequilibrium testing and logistic regression analyses were performed. Neither maternal nor paternal smoking increased $\mathrm{CL} / \mathrm{P}$ risk; odds ratios $(\mathrm{OR}): 1.2,95$ confidence intervals $(\mathrm{Cl})=0.7-2.0$ and $\mathrm{OR}: 1.0,95 \%$ $\mathrm{Cl}=0.6-1.6$, respectively. Carriership of the polymorphic Val105 allele in mothers may increase $\mathrm{CL} / \mathrm{P}$ risk, OR: $1.5,95 \% \mathrm{Cl}=0.96-2.5$. Children homozygous for the Val105 allele may show an increased risk of $\mathrm{CL} / \mathrm{P}$, OR: $2.2,95 \% \mathrm{Cl}=0.8-6.4$. Maternal smoking tended to increase $\mathrm{CL} / \mathrm{P}$ risk in mothers and children carrying Val105 alleles, $\mathrm{OR}=1.9,95 \% \mathrm{Cl}=0.9-4.0$ and $\mathrm{OR}=2.2,95 \% \mathrm{Cl}=0.98-4.9$, respectively. The highest risk for $\mathrm{CL} / \mathrm{P}$ in children carrying Val105 alleles with a smoking father was $1.7,95 \% \mathrm{Cl}=0.8-3.5$. The GSTP1 I105V polymorphism in mothers and/or children either alone or in combination with maternal smoking may contribute to $\mathrm{CL} / \mathrm{P}$ risk. Although of borderline significance, these results may underline the importance of smoking cessation in the periconception period for the prevention of $\mathrm{CL} / \mathrm{P}$ in future generations. European Journal of Human Genetics (2008) 16, 358-366; doi:10.1038/sj.ejhg.5201973; published online 9 January 2008

Keywords: detoxification; gluathione S-transferase P1; gene-environment; cleft; periconception; single nucleotide polymorphism; smoking

*Correspondence: Dr RPM Steegers-Theunissen, Department of Obstetrics and Gynecology, Erasmus MC University Medical Center, PO Box 2040, Rotterdam 3000 CA, The Netherlands.

Tel: + 3110 4636886; Fax: + 3110 4636815; E-mail: r.steegers@erasmusmc.nl

${ }^{9}$ Current address: Department of Clinical Genetics, Academic Hospital Maastricht, Maastricht, The Netherlands. Received 24 April 2007; revised 3 October 2007; accepted 15 November 2007; published online 9 January 2008 


\section{Introduction}

Orofacial clefts are complex congenital malformations with a multifactorial aetiology. ${ }^{1}$ In addition to genetic predispositions, environmental factors, such as maternal smoking during pregnancy, are strongly suggested to be involved in the pathogenesis of nonsyndromic orofacial clefts. $^{1-4}$

Several mechanisms for the detrimental actions of tobacco use have been proposed. Smoking increases the levels of carbon monoxide, which has a high affinity for haemoglobin, ${ }^{5}$ thereby decreasing the availability of oxygen to the embryo. Both hypoxia and nicotine lead to vasoconstriction of foetal and maternal blood vessels further reducing the supply of oxygen and essential nutrients to the embryonic tissues during the critical period of palatogenesis. Studies in mice have indeed revealed that maternal respiratory hypoxia increases the incidence of cleft lip with or without cleft palate (CL/P). ${ }^{6}$ Moreover, our group demonstrated the importance of vitamins and minerals in the pathogenesis of these congenital malformations. ${ }^{7-9}$ On the other hand, smoking may affect the expression of genes involved in palatogenesis, such as matrix metalloproteinases, ${ }^{10}$ or modify the concentration of important transcription factors, including folate. ${ }^{11,12}$ Moreover, allelic variants in several candidate genes for clefting, such as TGF $\alpha$, TGF $\beta 3$ and MSX1, demonstrated an interaction with smoking on CL/P risk. ${ }^{13-14}$

Current studies have mainly focused on the role of maternal exposures and congenital malformations in the offspring, as the mother is the environment of the intrauterine development of the child. However, the genetic background of the child is derived from both parents, whose gametes may be affected by lifestyle factors. ${ }^{15}$ Therefore, paternal lifestyle factors, such as smoking, may generate cytotoxic effects ${ }^{16}$ and could as such contribute to orofacial clefts in newborns.

The toxicity of smoking during embryogenesis varies in time, dose and frequency of exposure, and is dependent on metabolism and transfer of the toxins from the mother to the embryo. Therefore, the detoxification capacity of the parents as well as (extra)embryonic tissues may play a role in the aetiology of orofacial clefts. Glutathione $S$-transferase P1 (GSTP1), located on chromosome 11q13, is part of the superfamily of glutathione $S$-transferases (GSTs), involved in the detoxification of electophilic compounds by glutathione conjugation. ${ }^{17}$ So far, GSTP1 is the only isoform that is expressed in the placenta and in the developing embryo as early as 8 weeks of gestation. ${ }^{18,19}$

Genetic variations in (detoxification) enzymes may alter their functionality. We previously demonstrated that smoking mothers carrying the glutathione S-transferase Theta 1 (GSTT1)-null genotype had a three-fold increased risk for a child with a nonsyndromic orofacial cleft compared to nonsmokers with at least one functioning allele. The risk was almost five times greater in mothers and infants both having the GSTT1-null genotype. ${ }^{3}$ These findings have been confirmed by Lammer et al, ${ }^{20}$ who also revealed an interaction between the glutathione $S$-transferase M1 (GSTM1)-null genotype and maternal smoking on $\mathrm{CL} / \mathrm{P}$ risk. Similarly, polymorphisms in endothelial nitric oxide synthase, an enzyme involved in folate-homocysteine metabolism, affect $\mathrm{CL} / \mathrm{P}$ risk in combination with maternal smoking. ${ }^{21}$

For GSTP1, the I105V polymorphism, an amino-acid change of isoleucine to valine at codon 105 in exon 5, leads to decreased enzyme activity. ${ }^{22}$ GSTP1 is important in the detoxification of toxic compounds present in tobacco smoke. ${ }^{23}$ Just recently, Ramirez et al ${ }^{24}$ and Shi et al ${ }^{25}$ could not find an association between the GSTP1 I105V polymorphism and CL/P. However, in their unadjusted Danish data, they showed a two-fold increased $\mathrm{CL} / \mathrm{P}$ risk in homozygous $I 105 \mathrm{~V}$ foetuses with a smoking mother. ${ }^{25}$ Data on paternal smoking were not available in their study. Studies in knockout mice lacking gstp1 in a clean environment did not result in abnormal phenotypes. Their development was affected, however, when exposed to toxicants only. ${ }^{26}$

The aims of this study were (1) to investigate the GSTP1 I105V polymorphism in case and control triads in a Dutch population (mother, father, child) and (2) to evaluate the interactions between this polymorphism and periconception parental smoking and orofacial cleft risk.

\section{Materials and methods \\ Study population}

We performed a case-control triad (mother, father, child) study at the Radboud University Nijmegen Medical Center in Nijmegen and at the Erasmus MC, University Medical Center in Rotterdam in The Netherlands, and recruited 485 nonsyndromic orofacial cleft (395 CL/P and 90 cleft palate (CP)) and 274 control triads between October 1998 and August 2002. The participation rate of the cases was $72 \%$. The study design has been described in detail by Van Rooij et al. $^{3}$ In summary, case families were recruited in collaboration with the 10 largest cleft lip and palate teams in The Netherlands and the parents and patients organization for clefts (VSOP/BOSK). In every cleft lip and palate team, the orofacial cleft was classified and diagnosed as being nonsyndromic by a clinician according to a standard registration form developed by the Dutch Association for Cleft Palate and Craniofacial Anomalies (NVSCA). ${ }^{27}$ The control triads were parents and their healthy child without a major congenital malformation, enrolled by the case parents, for example, friends, acquaintances or neighbours, and by nurseries and public health centres in Nijmegen and surroundings. Only one affected child per family was included in the study. The controls were not related to the cases. The study moment was chosen at approximately 14 months after the delivery of the index child. From these 
485 case and 274 control triads, DNA for genotyping was available for $271 \mathrm{CL} / \mathrm{P}, 63 \mathrm{CP}$ and 233 control triads, seven $\mathrm{CL} / \mathrm{P}$ and eight control triads were excluded due to genotyping errors. Also, incomplete triads consisting of one or two non-Dutch non-Caucasian parents, consanguineous parents and triads for which not all periconception data were known were excluded. Owing to the rather small numbers in the CP group and the presumed different aetiology of CP compared to CL/P, we did choose to analyse the $\mathrm{CL} / \mathrm{P}$ group only. Owing to the poor quality of the DNA samples isolated from the buccal swabs, any GSTP1 data either for the mother, father or the child were available for $155 \mathrm{CL} / \mathrm{P}$ triads and 195 control triads.

The Central Committee of Medical Research with Humans in The Hague, The Netherlands and the local Medical Ethical Committees of all participating hospitals approved the study protocol. A written informed consent was obtained from every participant before participation.

\section{Data collection}

A general questionnaire was mailed to all parents and completed at home. The questionnaire was checked for completeness and consistency by the researcher in a personal interview during a hospital visit or by a telephone interview. Smoking was defined as the use of tobacco (cigarettes, cigars or pipe) in the periconception period. Data on potential confounders such as parental age, education, a family history for clefts and periconception health and lifestyle factors, such as any use of alcohol, medication (other than contraceptives, including iron supplements) and multivitamins, were extracted. Periconception conditions that could affect the maternal detoxification capacity, such as liver and renal diseases of the mother, were also recorded. The educational level was categorized into low (primary/lower vocational/intermediate secondary/intermediate vocational) and high (higher secondary/higher vocational or university) education. A family history for clefts was defined as two or more first (brothers, sisters, parents, children), second or third degree affected relatives of the index child. We did not choose to define a positive family history as one or more affected first, second or third degree relatives as one affected family member could still represent a sporadic case. The maternal periconception period was defined as the period of 3 months before conception until 3 months after conception, and that of the father as 3 months before conception until 2 weeks after conception.

For genotyping, DNA from mothers, fathers and children were extracted from stored blood samples or buccal swabs. The majority of the DNA of the children was obtained through buccal swabs, due to parental refusal to have a blood sample taken from the child. These buccal swabs were taken by the researcher or the parents of the child. The standardized instructions for taking the buccal swabs from the inner side of both cheeks by the case and control parents were the same.

\section{Laboratory determinations}

Genomic DNA was isolated from whole blood using the Puregene ${ }^{\circledR}$ genomic DNA isolation kit according to the instructions of the manufacturer (BIOzym, Landgraaf, The Netherlands). The buccal cell DNA was isolated from cheek cells as described previously. ${ }^{28}$ After preparation, the genomic DNA was stored at $4^{\circ} \mathrm{C}$ until use.

The GSTP1 exon 5 polymorphism was detected by polymerase chain reaction (PCR). ${ }^{28}$ The digestion of GSTP1 PCR products, using Alw26I restriction enzyme, resulted in fragments of 105 and $327 \mathrm{bp}$ for the non-polymorphic Isoleucine105 allele and 105, 107 and $220 \mathrm{bp}$ for the variant Valine105 allele. Sigma-Genosys Ltd. (Pampisford Cambrigdeshire, United Kingdom) synthesized all primers. Chemicals needed for PCR were purchased from Promega (Madison, WI, USA). The primers used were PiF2306: 5'-GT AGTTTGCCCAAGGTCAAG-3' and PiR2721: 5'-AGCCACC TGAGGGGTAAG-3' ${ }^{29}$ Based on the above described PCR analyses, all individuals could be divided into homozygote wild-type, heterozygote or homozygote variant genotypes. For accuracy, all genotyping was performed by one technician and checked by another, whereas the anonymized samples of the case and control groups were analysed together and decoded afterwards.

\section{Statistical analyses}

The data for age were compared between the study groups by Wilxocon's rank sum tests. All other variables were tested by $\chi^{2}$ test. The Fisher's exact (two-sided) test was used if cells containing less than the expected count of five occurred in the analysis. The risk for CL/P was estimated by odds ratios (OR) with 95\% confidence intervals (CI) where wild-type genotypes served as reference. Hardy-Weinberg equilibrium was tested by $\chi^{2}$ test and the transmission disequilibrium test (TDT) was performed to assess linkage disequilibrium between the polymorphic allele and CL/P risk. Risk estimates for the interaction between the GSTP1 Val105 allele and parental smoking were computed by logistic regression analyses, in which non-exposed homozygote wild types served as reference.

Potential confounders were evaluated by logistic regression analyses. With the exception of the variable of age, all possible confounders were entered in the multivariate model as a dichotomous variable. Significance was defined as $P \leq 0.05$ (two-sided). All statistical analyses were performed using SAS Statistical Analysis System version 8.2 (SAS institute Inc., Cary, NC, USA).

\section{Results}

The demographics of the triads and periconception exposures of the parents are depicted in Table 1 . Mothers 
of a child with a CL/P were less educated and more CL/P children were boys compared to the controls $(P \leq 0.05)$. Children with a CL/P were slightly older at the study moment $(P \leq 0.01)$ and their fathers tended to use more medication periconceptionally $(P=0.06)$ than controls. Nine case mothers and two controls used topical corticosteroids (Pulmicort ${ }^{\circledR}$ or Beclomethasone in eight case and two control mothers, one case mother used Hydrocortisone for dermatological problems). None of the mothers used anti-epileptic drugs, retinoids or other anti-folates, such as methrotrexate. Two case and one control mothers suffered from diabetes mellitus during pregnancy. Only one control child had a family history for clefts compared to nine children with $\mathrm{CL} / \mathrm{P}$. Four $\mathrm{CL} / \mathrm{P}$ mothers and five case fathers had a cleft compared to none of the controls. No maternal liver or renal diseases were reported in the periconception period.

Overall, neither maternal nor paternal smoking was a risk factor for $\mathrm{CL} / \mathrm{P}, \mathrm{OR}$ : $1.2,95 \% \mathrm{CI}=0.7-2.0$ and $\mathrm{OR}=1.0,95 \% \mathrm{CI}=0.6-1.6$, respectively. When nonsmoking mothers with a smoking partner were classified as smokers and vice versa, smoking was not a significant risk factor for CL/P, OR: $0.9,95 \% \mathrm{CI}=0.6-1.5$.

All the GSTP1 genotypes both in cases and controls were in Hardy-Weinberg equilibrium. The allele frequency of the variant Val105 allele was 37\% in CL/P cases and 33\% in controls. The GSTP1 Val105 allele was not transmitted significantly more frequently from heterozygous parents to the $\mathrm{CL} / \mathrm{P}$ child than the expected $50 \%$ (TDT; $P>0.05$; $n=69 \mathrm{CL} / \mathrm{P}$ and 95 control triads).

Table 2 depicts the associations between the GSTP1 genotypes and CL/P risk. Heterozygosity or homozygosity for the Val105 allele in mothers, albeit not significantly, increased CL/P risk 1.5-fold, OR: $1.5,95 \% \mathrm{CI}=0.9-2.5$ and OR $1.5,95 \% \mathrm{CI}=0.7-3.2$, respectively. Children carrying two Val105 alleles had a 2.2-fold increased CL/P risk, OR: $2.2,95 \% \mathrm{CI}=0.8-6.4$. Of the $16 \mathrm{Val105} / \mathrm{Val105}$ children (nine CL/P and seven controls), two CL/P and two control mothers were homozygous as well, 11 (seven CL/P and four controls) were heterozygous and from one control mother the genotype was unknown. Of the fathers of these children, five (four $\mathrm{CL} / \mathrm{P}$ and one control) were homozygous as well and 11 heterozygous (five CL/P and six controls). Of the nine CL/P children homozygous for the Val105 allele, two had a cleft lip, three a cleft lip with a cleft alveolus and four a cleft lip with a CP.

The results of the interaction analyses of the GSTP1 genotype and parental smoking in the periconception period are demonstrated in Table 3. Mothers and/or their children carrying Val105 alleles had a nearly two-fold risk for $\mathrm{CL} / \mathrm{P}$ when the mothers smoked in the periconceptional period. When smoking fathers were excluded in this analysis to correct for possible passive smoking, the risk for a child carrying Val105 alleles and a smoking mother for $\mathrm{CL} / \mathrm{P}$ was OR: $2.3,95 \% \mathrm{CI}=0.5-11.9$. This is in contrast to
Table 1 Demographics of the case and control triads of mother, father and child ${ }^{\mathrm{a}}$

\begin{tabular}{|c|c|c|}
\hline & $C L / P$ & Controls \\
\hline Mothers & $N=131$ & $N=171$ \\
\hline $\begin{array}{l}\text { Age (years) } \\
(\text { median (P5-P95)) }\end{array}$ & $30.5(25.0-37.0)$ & $30.8(25.2-37.2)$ \\
\hline $\begin{array}{l}\text { Low education } \\
(n, \% \text { yes })^{\mathrm{c}}\end{array}$ & $80(61.5)$ & $80(46.8)^{*}$ \\
\hline $\begin{array}{l}\text { Affected with clefts } \\
\text { ( } n, \% \text { yes) }\end{array}$ & $4(3.1)$ & $0^{* \star \star}$ \\
\hline \multicolumn{3}{|c|}{ Periconception use of ( $n, \%$ any use $)^{\mathrm{d}}$} \\
\hline Medication $^{\mathrm{e}}$ & $43(33.1)$ & $46(26.9)$ \\
\hline Multivitamins & $18(13.7)$ & $24(14.0)$ \\
\hline Alcohol & $57(43.5)$ & $84(49.1)$ \\
\hline Smoking ${ }^{f}$ & $34(26.0)$ & $40(23.4)$ \\
\hline Fathers & $N=126$ & $N=155$ \\
\hline $\begin{array}{l}\text { Age (years) } \\
(\text { median (P5-P95)) }\end{array}$ & $33.7(27.4-41.4)$ & $34.0(26.9-43.3)$ \\
\hline $\begin{array}{l}\text { Low education } \\
(n, \% \text { yes })^{\mathrm{c}}\end{array}$ & $72(57.1)$ & $81(52.3)$ \\
\hline $\begin{array}{l}\text { Affected with clefts } \\
(n, \% \text { yes) }\end{array}$ & $5(4.0)$ & $0^{\star \star \star *}$ \\
\hline \multicolumn{3}{|c|}{ Periconception use of ( $n, \%$ any use $)^{\mathrm{g}}$} \\
\hline Medication $^{\mathrm{e}}$ & $24(19.1)$ & $17(11.0)$ \\
\hline Multivitamins & $11(8.7)$ & $10(6.5)$ \\
\hline Alcohol & $108(85.7)$ & $132(85.2)$ \\
\hline Smoking ${ }^{f}$ & $51(40.5)$ & $63(40.7)$ \\
\hline \multirow{4}{*}{$\begin{array}{l}\text { Children } \\
\text { Age (months) } \\
\text { (median (P5-P95)) }^{\mathrm{h}} \\
\text { Boys ( } n \text {, \% yes) } \\
\text { Positive family history } \\
(n, \% \text { yes })^{\mathrm{i}}\end{array}$} & $N=94$ & $N=131$ \\
\hline & $15.6(12.0-50.4)$ & $14.4(8.4-36.0)^{\star *}$ \\
\hline & $63(67.0)$ & $69(52.7)^{\star}$ \\
\hline & $9(9.6)$ & $1(0.8)^{\star * \star}$ \\
\hline
\end{tabular}

$\mathrm{CL} / \mathrm{P}$, cleft lip with or without cleft palate.

${ }^{*} \chi^{2}$-test $P \leq 0.05 ;{ }^{* *} \chi^{2}$-test $P \leq 0.01 ; \mathrm{CL} / \mathrm{P}=$ cleft lip with or without cleft palate; ${ }^{* * *}$ Fisher's Exact test $P \leq 0.05$.

${ }^{a}$ Only those individuals are analysed from whom genetic data were available.

${ }^{b}$ Age at the delivery of the index child; missings: two control fathers. 'Low: primary/lower vocational/intermediate secondary/intermediate vocational education; missing: one $\mathrm{CL} / \mathrm{P}$ mother.

${ }^{\mathrm{d}}$ Defined as the period of 3 months before to 3 months after conception of the index child.

${ }^{\mathrm{e}}$ The use of any medication other than oral contraceptives, including iron supplements; missing: one $\mathrm{CL} / \mathrm{P}$ mother.

${ }^{f}$ Any smoking of tobacco such as cigarettes, cigars or pipe.

${ }^{9}$ Defined as the period of 3 months before to 2 weeks after conception of the index child.

${ }^{\mathrm{h}}$ Age at study moment, missings: three $\mathrm{CL} / \mathrm{P}$ children.

'Defined as the presence of two or more, first, second or third degree relatives with clefts of the index child.

smoking fathers carrying this risk allele, OR: 0.9, 95\% $\mathrm{CI}=0.5-1.8$. The highest $\mathrm{CL} / \mathrm{P}$ risk with paternal smoking was observed for children with Val105 alleles: OR: 1.7, 95\% $\mathrm{CI}=0.8-3.5$. Since this effect could possibly be the result of a simultaneously smoking mother, we re-analysed these data in children with a smoking father only, which revealed a risk estimate of $1.4,95 \% \mathrm{CI}=0.5-3.6$ compared 
Table 2 Glutathione S-transferase P1 (GSTP1) genotypes and the risk of cleft lip with or without cleft palate (CL/P)

\begin{tabular}{|c|c|c|c|c|c|c|}
\hline & $C L / P$ & Controls & $O R$ & $95 \% \mathrm{Cl}$ & $O R$ & $95 \% \mathrm{Cl}^{\mathrm{a}}$ \\
\hline $\begin{array}{l}\text { GSTP1 genotype } \\
\text { Mother }\end{array}$ & $N=131$ & $N=171$ & & & & \\
\hline Homozygote variant & $16(12.2)$ & $18(10.5)$ & 1.5 & $0.7-3.2$ & 1.5 & $0.96-2.5$ \\
\hline Heterozygote & $70(53.4)$ & $77(45.0)$ & 1.5 & $0.9-2.5$ & & \\
\hline \multirow[t]{2}{*}{ Homozygote wild type } & $45(34.4)$ & $76(44.4)$ & 1.0 & Reference & 1.0 & Reference \\
\hline & $N=126$ & $N=155$ & & & & \\
\hline \multicolumn{7}{|l|}{ Father } \\
\hline Homozygote variant & $18(14.3)$ & $17(11.0)$ & 1.3 & $0.6-2.7$ & 0.9 & $0.6-1.5$ \\
\hline Heterozygote & $57(45.3)$ & $78(50.3)$ & 0.9 & $0.5-1.4$ & & \\
\hline \multirow[t]{2}{*}{ Homozygote wild type } & $51(40.5)$ & $60(38.7)$ & 1.0 & Reference & 1.0 & Reference \\
\hline & $N=94$ & $N=131$ & & & & \\
\hline \multicolumn{7}{|l|}{ Child } \\
\hline Homozygote variant & $9(9.6)$ & $7(5.3)$ & 2.2 & $0.8-6.4$ & 1.4 & $0.8-2.4$ \\
\hline Heterozygote & $49(52.1)$ & $63(48.1)$ & 1.3 & $0.8-2.3$ & & \\
\hline Homozygote wild type & $36(38.3)$ & $61(46.6)$ & 1.0 & Reference & 1.0 & Reference \\
\hline
\end{tabular}

OR, odds ratio, $95 \% \mathrm{Cl}, 95 \%$ confidence interval.

${ }^{a}$ Odds ratio with $95 \% \mathrm{Cl}$ comparing the homozygote variant (Val105/Val105) and heterozygote (Val105/lleu105) genotypes to the homozygote wildtype (lleu105/lleu105) genotypes.

to wild-type nonsmokers. Our conclusions were only marginally affected after adjustment for parental age, education, a positive family history for clefts or the use of alcohol, medication and multivitamins (data not shown).

To increase the validity of the results, we also performed all above-mentioned analyses for those triads for which genetic data were available for the mother, father and child ( $n=69 \mathrm{CL} / \mathrm{P}$ and 95 control triads). Significant differences between $\mathrm{CL} / \mathrm{P}$ and controls were observed for the male child $(P \leq 0.05)$ and fathers using medication periconceptionally $(P=0.05)$. Again, more case parents had clefts themselves and case children more often had a positive family history for clefts compared to controls $(P<0.05)$. Homozygosity for the Val105 polymorphism in mothers and in children approximately three-fold increased $\mathrm{CL} / \mathrm{P}$ risk, OR: 2.8, 95\% $\mathrm{CI}=0.99-7.7$ and $\mathrm{OR}: 2.8$, $95 \% \mathrm{CI}=0.9-8.7$, respectively. Homozygosity in fathers increased $\mathrm{CL} / \mathrm{P}$ risk about two-fold, OR: 1.8, 95\% $\mathrm{CI}=0.6-5.3$. The risk estimates for the interaction between maternal or child carriership of GSTP1 Val105 alleles and maternal smoking were only marginally altered, OR:1.9, 95\% CI $=0.8-4.9$ and OR: $1.9,95 \% \mathrm{CI}=0.7-4.7$. However, for children, almost similar risk estimates were observed in carriers without periconception smoking exposure, OR: $1.9,95 \% \mathrm{CI}=0.9-4.2$. These results could thus point to a more deleterious effect of smoking rather than a geneenvironment effect. The interaction between the carriership of GSTP1 Val105 alleles in fathers or children and periconception smoking of the father were unchanged, OR: $1.0,95 \% \mathrm{CI}=0.4-2.3$ and $\mathrm{OR}: 1.8,95 \% \mathrm{CI}=0.7-4.3$, respectively.

Of the parents from whom genetic data were available, approximately $62 \%$ of the controls were recruited by cases and $38 \%$ by nurseries and public health centres in the surroundings of Nijmegen. This was due to the lack of permission of some participating centres to recruit controls by the case families. The social background appeared to be different between the control groups. Because smoking and social background are associated, we analysed the control groups separately and showed that the smoking frequencies were comparable, for example, mothers: 25.7 versus $19.7 \%, P=0.37$, and fathers: 44 versus $34.6 \%, P=0.25$. Also comparing case mothers with both control groups separately did not change CL/P risk by smoking, OR: 1.0, 95\% $\mathrm{CI}=0.6-1.8$ and OR: $1.4,95 \% \mathrm{CI}=0.7-2.9$, respectively. Similar results were observed in the fathers, OR: 0.9, 95\% $\mathrm{CI}=0.5-1.5$ and OR: $1.3,95 \% \mathrm{CI}=0.7-2.5$, respectively. The distribution of the GSTP1 polymorphism was independent of control selection and adjustment for educational level did not alter the results.

Case mothers tended to use medication more frequently compared to controls $(P>0.05)$. To further reduce aetiologic heterogeneity, we also performed all above-mentioned analyses excluding mothers using drugs or having illnesses known to be associated with clefts, such as topical corticosteroids and diabetes. Comparable results to our initial analyses were revealed.

\section{Discussion}

This study suggests that the GSTP1 I105V polymorphism in the mother or in the child, alone or in combination with periconception maternal smoking, increases CL/P risk.

Although the results are of borderline significance, the hypothesis that a decreased detoxification of toxic compounds present in tobacco smoke, as a result of the GSTP1 I105V polymorphism, interferes with normal development 
Table 3 The interactions between glutathione S-transferase P1 (GSTP1) genotype and parental periconception smoking on the risk of cleft lip with or without palate $(\mathrm{CL} / \mathrm{P})$

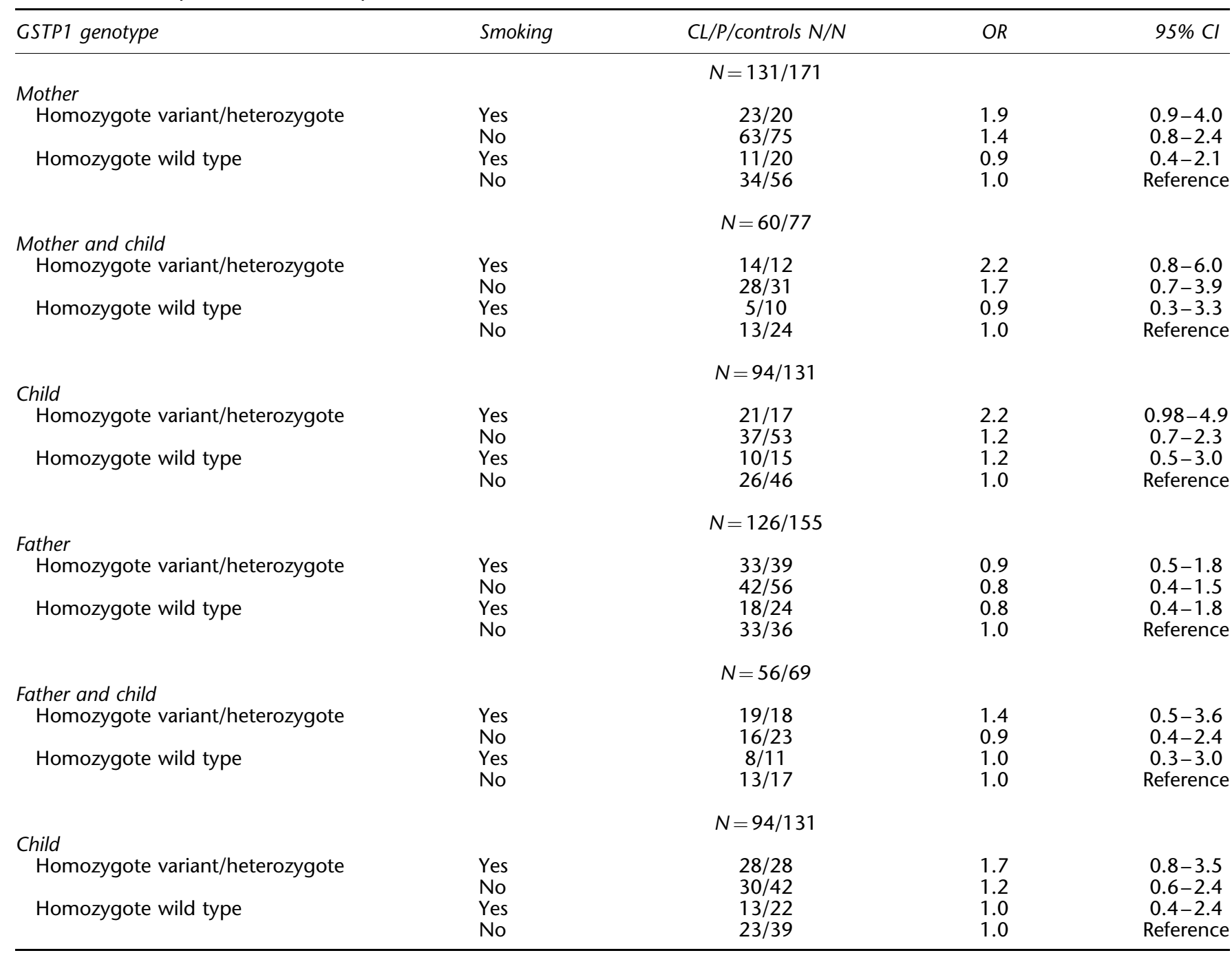

OR, odds ratio, $95 \% \mathrm{Cl}, 95 \%$ confidence interval.

of the lip, alveolus and/or palate is supported. Also, our results on the interaction between smoking and the I105V polymorphism are in line with data of Shi et al. ${ }^{25}$

The I105V polymorphism has also been associated with other health effects, such as lung cancer, bladder cancer and head and neck cancers. ${ }^{30-32}$ A common mechanism for polymorphisms in GSTP1 and smoking, in the aetiology of both cancer and orofacial clefts could be an increase in DNA damage due to the decreased detoxification of toxins and carcinogens. In this context, Liu et al demonstrated that individuals with susceptible GSTP1 genotypes experienced an increased risk of DNA damage elicited by pesticide exposure. ${ }^{33}$ This mechanism, however, does not explain why the cells of the lip, alveolus and/or palate, in particular, are vulnerable to DNA damage. From the nature of birth defects associated with maternal smoking, such as orofacial clefts, ${ }^{1-4}$ craniosynostosis, ${ }^{34}$ gastroschisis ${ }^{35}$ and congenital heart defects, ${ }^{36}$ one may suggest that smoking may have a detrimental affect on neural crest cell migration and differentiation, and on biologic processes, such as apoptosis, involved in the fusion of tissues.

Our results show a nonsignificant association between the GSTP1 Val105 allele and CL/P risk. It is not likely that the GSTP1 I105V polymorphism is a candidate locus for $\mathrm{CL} / \mathrm{P}$, as none of the homozygous GSTP1 Val105 mothers had clefts themselves and there was no preferential transmission of the Val105 allele from heterozygous parents to the $\mathrm{CL} / \mathrm{P}$ children. This indicates, especially in a complex malformation as clefts, that other genes than GSTP1 are mainly involved. 
The limitations and strengths of the study have to be discussed. Although our study populations consisted of larger numbers, genetic data were only available of 155 $\mathrm{CL} / \mathrm{P}$ and 195 control triads. This was mainly due to the low amount and the poor quality of the DNA of the children, isolated from buccal swabs. All clefts were surgically closed before the study moment. Moreover, the buccal swabs were taken by the researcher or the parents of the child. The standardized instructions for taking the buccal swabs by the case and control parents were the same and the swabs were taken from the inner side of both cheeks. Therefore, it is not very likely that the place of sampling explains the poor quality of the DNA. We also speculated that differences in oral mucosa between children with or without CL/P could explain the quantity or quality of the DNA samples. However, so far differences in oral mucosa between children with and without CL/P are not reported. Based on our current experience and that of others, it has become clear that the DNA concentration derived from buccal swabs is highly dependent on the quality of the medium (antibiotics, fungicides, and so on) in which the brushes are preserved after sampling. This is our main explanation of the poor DNA quality and resulting low numbers. In future studies, we would advise, when blood of the children is not available, to isolate DNA from saliva samples.

Strengths of the study are that the data are substantiated by the analyses of the complete triads, and that our allele frequencies of the GSTP1 I105V polymorphism were comparable with those published by others. ${ }^{25,29}$ Moreover, the case-parents design allows for the inclusion of both the parental and child data and for transmission equilibrium testing.

This study adds to the current knowledge on smoking and orofacial clefts. ${ }^{1-4}$ Our data on smoking were collected retrospectively, which may introduce the possibility of recall bias. We minimized this issue by standardizing the design and moment of data collection at around 14 months after delivery, which is the same season as the child's first anniversary to facilitate recall. Nevertheless, our figures on maternal smoking were comparable to other Dutch data from the same period being in the range of $25-35 \% .{ }^{37,38}$ Evidence that recall bias is not frequent in case-control studies and that it is merely non-differential further substantiates the validity of our data. ${ }^{38,39}$ However, maternal smoking alone was not a risk factor for $\mathrm{CL} / \mathrm{P}$ in our study. It is conceivable that in the Dutch population, maternal smoking only increases CL/P risk in combination with a specific genetic background, for example, particular GSTP1 or GSTT1 genotypes. ${ }^{3}$

Our data are unique because data of the father are also included. We hypothesized that the paternal GSTP1 Val105 allele, alone or in combination with smoking, may induce genotoxic effects in spermatozoa and ultimately could contribute to $\mathrm{CL} / \mathrm{P}$ in offspring. It is known that smokers have higher levels of DNA damage in their sperm. ${ }^{16}$ In this context, the presence of the GSTP1 enzyme in seminal fluid further substantiates its role in the protection of spermatozoa against (oxidative) damage. ${ }^{40}$ However, our results did not reveal a significant association between the paternal GSTP1 Val105 allele, alone or in combination with paternal smoking and CL/P offspring. Possible explanations may be that DNA damage in sperm can be repaired to a certain extent, that alternative metabolic pathways are being used or that other GSTs compensate for the deficient GSTP1 enzyme. ${ }^{41}$

Besides the intrinsic detoxification pathways, exogenous antioxidants present in fruits and vegetables are also an important defence against toxic compounds. In our population, the antioxidant intake through supplements was comparable between cases and controls. However, in 2004, we demonstrated in the same study group that mothers of a child with an orofacial cleft had a lower dietary intake of foods rich in antioxidants compared to controls. ${ }^{8}$ Those mothers, when also carrying the Val105 allele and smoking, may be at the highest risk. However, due to the relatively small sample size, this could not be investigated. In this regard, it is of interest that Persson et $a l^{42}$ revealed that the addition of $250 \mathrm{~g}$ of mixed vegetables to a normal diet reduced the levels of GSTP1 mRNA in human lymphocytes. The authors speculate on a compensatory downregulation of the endogenous antioxidant system as a result of the increased external supply. ${ }^{42}$ Thus, women who want to become pregnant should stop smoking and increase their dietary intake of antioxidants independent of their genetic background.

In conclusion, our data suggest a possible role for the GSTP1 Val105 allele in mothers and children alone or in combination with maternal smoking, in the pathogenesis of nonsyndromic CL/P. These data should be further investigated in larger studies and in other populations as well. As the genetic constitution is not modifiable, these findings emphasize the importance of preconception counseling of mothers-to-be on amendable lifestyle factors, such as smoking and dietary habits, in order to reduce the birth prevalence of $\mathrm{CL} / \mathrm{P}$ in future generations. Thus, our data support the advice of cessation of smoking during pregnancy and support the results of a recent metaanalysis. $^{4}$

\footnotetext{
Acknowledgements

We thank the participating cleft lip and palate teams, the organization for patients with clefts and their parents (BOSK) and their coordinators (BOSK, Mr B van Beek; Rijnstate Hospital Arnhem, Dr W Brussel; Free University Hospital Amsterdam and Erasmus MC University Medical Center Rotterdam, Professor Dr B Prahl-Andersen; University Hospital Groningen, Professor Dr SM Goorhuis-Brouwer; Medical Center Leeuwarden, Dr JJ van der Biezen; Radboud University Nijmegen Medical Center, Professor AM Kuijpers-Jagtman; St Elisabeth Hospital Tilburg, Dr JG Daggers; University Medical Center Utrecht, Dr AB
} 
Mink van der Molen and Sophia Hospital Zwolle, Dr P Houpt). We acknowledge the nurseries and public health centres for their participation in the recruitment of control mothers. We are very grateful to Mrs $M$ van der Doelen and Dr C van Oostrom, chief nurse officer and head of the outpatient pediatric clinic Radboud University Nijmegen Medical Center, respectively, for their assistance, $\mathrm{Dr} C$ Vermeij-Keers for the opportunity to use the registration system of the Dutch Association for Cleft Palate and Craniofacial Anomalies, Mrs A Pellegrino and Mrs L Lemmens for data entry and Mr W Lemmens for data management. There are no conflicts of interest.

\section{References}

1 Murray JC: Gene-environment causes of cleft lip and/or palate. Clin Genet 2002; 61: 248-256.

2 Bille C, Olsen J, Vach W et al: Oral clefts and life style factors. A case-cohort study based on prospective Danish data. Eur J Epidemiol 2007; 22: 173-181.

3 van Rooij IALM, Wegerif MJ, Roelofs HM et al: Smoking, genetic polymorphisms in biotransformation enzymes, and nonsyndromic oral clefting: a gene-environment interaction. Epidemiology 2001; 12: 502-507.

4 Little J, Cardy A, Munger RG: Tobacco smoking and orofacial clefts: a meta-analysis. Bull World Health Organ 2004; 82: $213-218$

5 Townsend J, Wilkes H, Haines A, Jarvis M: Adolescent smokers seen in general practice: health, lifestyle, physical measurements, and response to antismoking advice. BMJ 1991; 303: 947-950.

6 Bailey LC, Johnston MC, Billet J: Effects of carbon monoxide and hypoxia on cleft lip in A/J mice. Cleft Palate Craniofac J 1995; 32: $14-19$.

7 Krapels IPC, van Rooij IALM, Ocke MC, van Cleef BAGL, KuijpersJagtman AM, Steegers-Theunissen RPM: Maternal dietary B vitamin intake, other than folate, and the association with orofacial cleft in the offspring. Eur J Nutr 2004; 43: 7-14.

8 Krapels IPC, van Rooij IALM, Ocke MC, West CE, van der Horst CMAM, Steegers-Theunissen RPM: Maternal nutritional status and the risk for orofacial cleft offspring in humans. J Nutr 2004; 134: 3106-3113.

9 van Rooij IALM, Ocke MC, Straatman H, Zielhuis GA, Merkus HMWM, Steegers-Theunissen RPM: Periconceptional folate intake by supplement and food reduces the risk of nonsyndromic cleft lip with or without cleft palate. Prev Med 2004; 39: 689-694.

10 Katono T, Kawato T, Tanabe $\mathrm{N}$ et al: Nicotine treatment induces expression of matrix metalloproteinases in human osteoblastic Saos-2 cells. Acta Biochim Biophys Sin (Shanghai) 2006; 38: 874-882.

11 Piyathilake CJ, Macaluso M, Hine RJ, Richards EW, Krumdieck CL: Local and systemic effects of cigarette smoking on folate and vitamin B-12. Am J Clin Nutr 1995; 60: 559-566.

12 Stark KD, Pawlosky RJ, Sokol RJ, Hannigan JH, Salem Jr N: Maternal smoking is associated with decreased 5-methylenetetrahydrofolate in cord plasma. Am J Clin Nutr 2007; 85: 796-802.

13 Romitti PA, Lidral AC, Munger RG, Daack-Hirsch S, Burns TL, Murray JC: Candidate genes for nonsyndromic cleft lip and palate and maternal cigarette smoking and alcohol consumption: evaluation of genotype-environment interactions from a population-based case-control study of orofacial clefts. Teratology 1999; 59: 39-50.

14 Shaw GM, Wasserman CR, Lammer EJ et al: Orofacial clefts, parental cigarette smoking, and transforming growth factoralpha gene variants. Am J Hum Genet 1996; 58: 551-561.

15 Steegers-Theunissen RPM, Van Iersel CA, Peer PG, Nelen WL, Steegers EAP: Hyperhomocysteinemia, pregnancy complications, and the timing of investigation. Obstet Gynecol 2004; 104: $336-343$.

16 DeMarini DM: Genotoxicity of tobacco smoke condensate: a review. Mutat Res 2004; 567: 447-474.
17 Hayes JD, Pulford DJ: The glutathione $S$-transferase supergene family: regulation of GST and the contribution of the isoenzymes to cancer chemoprotection and drug resistance. Crit Rev Biochem Mol Biol 1995; 30: 445-600.

18 van Lieshout EMM, Knapen MFCM, Lange WP, Steegers EAP, Peters WHM: Localization of glutathione $S$-transferases alpha and pi in human embryonic tissues at 8 weeks gestational age. Hum Reprod 1998; 13: 1380-1386.

19 Zusterzeel PLM, Peters WHM, De Bruyn MA, Knapen MFCM, Merkus HMWM, Steegers EAP: Glutathione $S$-transferase isoenzymes in decidua and placenta of preeclamptic pregnancies. Obstet Gynecol 1999; 94: 1033-1038.

20 Lammer EJ, Shaw GM, Iovannisci DM, Finnell RH: Maternal smoking, genetic variation of glutathione $S$-transferases, and risk for orofacial clefts. Epidemiol 2005; 16: 698-701.

21 Shaw GM, Iovannisci DM, Yang W et al: Endothelial nitric oxide synthase (NOS3) genetic variants, maternal smoking, vitamin use, and risk of human orofacial clefts. Am J Epidemiol 2005; 162: $1207-1214$

22 van Lieshout EMM, Roelofs HMJ, Dekker S et al: Polymorphic expression of the glutathione $S$-transferase P1 gene and its susceptibility to Barrett's esophagus and esophageal carcinoma. Cancer Res 1999; 59: 586-589.

23 Harries LW, Stubbins MJ, Forman D, Howard GC, Wolf CR: Identification of genetic polymorphisms at the glutathione $S$-transferase Pi locus and association with susceptibility to bladder, testicular and prostate cancer. Carcinogenesis 1997; 18: 641-644.

24 Ramirez D, Lammer EJ, Iovannisci DM, Laurent C, Finnell RH, Shaw GM: Maternal smoking during early pregnancy, GSTP1, and EPHX1 variants, and risk of isolated orofacial clefts. Cleft Palate Craniofac I 2007; 44: 366-373.

25 Shi M, Christensen K, Weinberg CR et al: Orofacial cleft risk is increased with maternal smoking and specific detoxification gene variants. Am J Hum Genet 2007; 80: 76-90.

26 Gonzalez FJ: The use of gene knockout mice to unravel the mechanisms of toxicity and chemical carcinogenesis. Toxicol Lett 2001; 120: 199-208.

27 Luijsterburg AMJ, Vermeij-Keers C: NVSCA-Registration cleft lip/ alveolus and cleft palate. Annual Report 1997. Department of Plastic Surgery, Erasmus MC University Medical Center, Rotterdam, The Netherlands, ISBN 90-76580-022. 1999.

28 Richards B, Skoletsky J, Shuber AP et al: Multiplex PCR amplification from the CFTR gene using DNA prepared from buccal brushes/swabs. Hum Mol Genet 1993; 2: 159-163.

29 Watson MA, Stewart RK, Smith GB, Massey TE, Bell DA: Human glutathione $S$-transferase P1 polymorphisms: relationship to lung tissue enzyme activity and population frequency distribution. Carcinogenesis 1998; 19: 275-280.

30 Miller DP, De Vivo I, Neuberg D et al: Association between selfreported environmental tobacco smoke exposure and lung cancer: modification by GSTP1 polymorphism. Int $J$ Cancer 2003; 104: 758-763.

31 Kellen E, Hemelt M, Broberg $\mathrm{K}$ et al: Pooled analysis and metaanalysis of the glutathione $S$-transferase P1 Ile 105Val polymorphism and bladder cancer: a HuGE-GSEC review. Am J Epidemiol 2007; 165: 1221-1230.

32 Cho CG, Lee SK, Nam SY: Association of the GSTP1 and NQO1 polymorphisms and head and neck squamous cell carcinoma risk. J Korean Med Sci 2006; 21: 1075-1079.

33 Liu YJ, Huang PL, Chang YF et al: GSTP1 genetic polymorphism is associated with a higher risk of DNA damage in pesticideexposed fruit growers. Cancer Epidemiol Biomarkers Prev 2006; 15: 659-666.

34 Källén K: Maternal smoking and craniosynostosis. Teratology 1999; 60: 146-150.

35 Cournot MP, Assari-Merabtene F, Vauzelle-Gardier C, Eléfant E: Maternal cigarette smoking during pregnancy and malformations. J Gynecol Obstet Biol Reprod (Paris) 2005; 34: 3S124-3S129. 
36 Källén K: Maternal smoking and congenital heart defects. Eur J Epidemiol 1999; 15: 731-737.

37 Crone MR, Hirasing RA, Burgmeijer RJF: Prevalence of passive smoking in infancy in the Netherlands. Patient Educ Couns 2000; 39: $149-153$.

38 Statistics Netherlands. General Social Survey (POLS). Data from 1999-2000 [Dutch].

39 Infante-Rivard C, Jacques L: Empirical study of parental recall bias. Am J Epidemiol 2000; 152: 480-486.
40 Raijmakers MTM, Roelofs HMJ, Steegers EAP et al: Glutathione and glutathione $S$-transferases A1-1 and P1-1 in seminal plasma may play a role in protecting against oxidative damage to spermatozoa. Fertil Steril 2003; 79: 169-172.

41 Ahmadi A, Soon-Chye NG: Fertilizing ability of DNA damages spermatozoa. J Exp Zool 1999; 284: 696-704.

42 Persson I, He L, Fang C, Normen L, Rylander R: Influence of vegetables on the expression of GSTP1 in humans - a pilot intervention study (Sweden). Cancer Causes Control 2000; 11: 359-361. 